\title{
Unrealistic optimism about diet-related risks: implications for interventions
}

\author{
BY MONIQUE M. RAATS AND PAUL SPARKS \\ Institute of Food Research, Earley Gate, Whiteknights Road, Reading RG6 $6 \mathrm{BZ}$
}

The Health of the Nation report (Department of Health, 1992) set targets for population dietary intake which will necessitate widespread changes in eating behaviour. The recent Committee on Medical Aspects of Health Policy report (Department of Health, 1994) indicates how these targets might be achieved by providing examples of practical strategies that people could adopt. However, despite the abundance of official recommendations and sources of information about dietary issues, there appears to have been relatively little change in the intake of certain nutrients at the population level. If the recent recommendations are to be heeded, it is likely that an emphasis on a general need for changes (even when combined with an indication of what those changes should or could be) needs to be supplemented by more effective means of influencing dietary choices.

Hand-in-hand with increasing and widespread acknowledgement of a link between diet and health, there has been both historical change in the direction of dietary advice (for a discussion of the evolution of dietary advice see Cannon, 1992) and some dispute between 'experts' about nutritional issues; it is often suggested that these have served to provoke some confusion in the public mind about dietary recommendations. To confound this problem, there has been a good deal of debate about where dietary advice efforts should be targeted; while some have suggested that strategies ought to be directed at the broader population level, others have voiced a preference for targeting 'at risk' individuals. This latter debate serves to raise a question mark for many people about the personal applicability of dietary advice. For whom is dietary advice relevant?

A number of researchers and practitioners involved in health promotion and health psychology are paying increasing attention to the 'unrealistic optimism' phenomenon which has been widely discussed as having important practical implications for health. In the present short review paper, we present a brief general discussion of dietary intervention strategies, outline the 'unrealistic optimism' phenomenon, critically assess its implications for the promotion of dietary change and give a brief review of recent research which has been addressing the issues raised. For the purpose of brevity, we shall concentrate on the reduction of fat consumption as the main dietary theme that we address.

\section{DIETARY INTERVENTIONS}

'Many public communication campaigns are hampered by poor conceptualization and inadequate formative evaluation research input. Lack of time, lack of money, and pressure from funding sources to "get on the map" are some of the reasons why formative research is skipped or conducted inadequately.' (Atkin \& Freimuth, 1989, cited by McGrath, 1991)

Reviews of dietary interventions are widely available in the literature (Glanz, 1985; Glanz et al. 1992; Glanz \& Eriksen, 1993; Winett et al. 1993; Andrien, 1994; Bowen \& 
Tinker, 1995). Here, we would like to focus on a few important considerations, indicated by the literature, that need to be taken into account by those planning intervention work.

First, there is some evidence that significant reductions in, for example, fat intake are possible through intervention studies, at least for some people. Henderson et al. (1990) describe an average reduction in percentage energy from fat from 39.1 to 20.9 over a 6-month period in a group ( $n$ 184) of 45-69-year-old women who were at increased risk of breast cancer. After 24 months, percentage of energy from fat for these women remained low at an average 22.6 (the control group showed a small, but statistically significant, decrease). Buzzard et al. (1990) report a reduction in percentage energy from fat from an average of 38.4-22.8 over a 3-month period in seventeen postmenopausal women with stage II breast cancer (a control group did not show a significant reduction in fat intake). Bowen et al. (1994) report that of nearly 2000 women in the Women's Health Trial (WHT) who faced an increased risk of breast cancer, $80 \%$ were able after 3 months to have reduced their fat intake by half (to $20 \%$ food energy from fat). Bowen \& Tinker (1995) also discuss the Multiple Risk Factor Intervention Trial (MRFIT) in which a large sample of male subjects were able to reduce their fat consumption by an average of 25-30\% . (Interestingly, Bowen \& Tinker (1995) also note 'Moreover, the husbands of the WHT participants reported dietary changes of a magnitude similar to or greater than that of men who had received direct intervention in MRFIT'.)

Second, many interventions consist of a variety of techniques, such that it is difficult to apportion influence to any single factor(s). While this is of more concern to some "health professionals' than to others, it does need to be borne in mind when methods are being adopted and modified from those currently reported in the literature.

Third, the studies which demonstrate the greatest changes in dietary behaviour are those studies in which subjects are highly motivated to make the changes and where the interventions have been relatively intensive (see Winett et al. 1993). One might expect, therefore, considerably less dramatic effects with intervention programmes (possessing much more limited per capita resources) that are directed at the general population.

Fourth, there are difficulties in accurately assessing fat intake at an individual level, although this is clearly an important requirement where tailored interventions are being planned: 'One of the difficulties in screening for a particular level of fat consumption has been the inadequacy of measurement instruments that are accurate, inexpensive, and easy to use in a mass screening setting' (Bowen et al. 1994). We return later to some practical and ethical issues associated with this problem.

\section{WHAT IS UNREALISTIC OPTIMISM?}

Unrealistic optimism refers to the tendency of people to report that they are less likely than the average person of their sex and age to experience a hazard (or more likely than the average person to experience a 'positive life event'). For example, there is by now a large body of evidence indicating that people say that they are less likely than the average other to experience a wide range of negative outcomes or hazards (for example, food poisoning, sunstroke or ulcers; Weinstein, 1987). Unrealistic optimism refers to a group tendency; not every person is unrealistically optimistic but the tendency is for more people to say that they are at below-average risk than to say that they are at above-average risk. Within a group, we do not know who is being unrealistic but we deduce that some are since we presume that risk is approximately 'normally distributed' 
(although this is contentious), with roughly equal numbers of people at above- and below-average risk. The claim of unrealistic optimism also presumes that the sample under investigation is representative of the relevant 'population' of people.

There have been different explanations for the unrealistic optimism phenomenon, some of them focusing on cognitive factors and some of them focusing on motivational factors. For example, Weinstein (1987) suggests that the phenomenon may arise because people are motivated to promote their own self-esteem and consequently compare themselves with others whom they consider to be at high risk, or that it is a form of 'defensive denial'; an attempt to avoid the anxiety one would feel from admitting a threat to well-being. Alternative explanations may be more cognitive and less motivational than these. For example, if hazards are low in their frequency of occurrence and not within the realm of people's experience, people may not only judge their own risks from these hazards as low but also fail to consider that these hazards are also unlikely to affect other people.

Furthermore, there is evidence that unrealistic optimism is positively related to 'controllability' (the more controllable the person's exposure to the hazard, the greater the degree of unrealistic optimism) and to the existence of stereotypes about those at risk (if stereotypes about 'at risk' people exist, the greater the degree of unrealistic optimism).

\section{WHY IS UNREALISTIC OPTIMISM IMPORTANT?}

'Optimistic biases in personal risk perceptions are important because they may seriously hinder efforts to promote risk-reducing behaviors'. (Weinstein, 1989)

The implications of unrealistic optimism in health-related domains of behaviour have long been of concern. Van der Pligt (1994) has suggested that an illusion of relative invulnerability to hazards might mean that people are less likely to adopt healthpromoting behaviours: 'If health risks primarily concern other people and not oneself there is no reason to adapt one's behaviour'.

Taylor \& Brown (1988) have put forward the interesting thesis that optimism might often be actually very useful; that optimism is a sign of healthy functioning. Depressed people, it seems, have fewer illusions (for example, of control, or about the likelihood of possible future events) than those who are not depressed. Taylor \& Brown (1988) suggest that positive illusions are a highly adaptive way of dealing with some negative 'information' from the environment. Dramatically, in a recent study (Taylor et al. 1992), gay men who tested seropositive showed more optimism about the effects of being exposed to acquired immunodeficiency syndrome than those who had been tested seronegative (all subjects were aware of their human immunodeficiency virus status). Taylor et al. (1992) suggest that under conditions of severe threat, illusions may be used as a way of dealing with the threat; while positive illusions are generally adaptive for ordinary experience, for people facing 'severe threats' they become 'especially important and exaggerated'. The Taylor \& Brown (1988) thesis is the subject of much ongoing debate (see also Taylor, 1989).

More generally, studies examining the relationship between perceptions of relative risk and actual behaviour have provided 'highly inconsistent' evidence (Hoorens, 1994). Some research has shown that optimism is related to taking fewer health precautions, 
some has shown that optimism is related to taking more precautions and some has found no relationship! Most significantly, there has been very little empirical research investigating the relationship between changes in perceived risk and changes in behaviour. Researchers engaged in this field of study have pointed to the need for longitudinal designs to enable such relationships to be properly investigated (e.g. Hoorens, 1994; van der Pligt, 1994; cf. Weinstein \& Nicolich, 1993).

\section{ARE PEOPLE UNREALISTICALLY OPTIMISTIC ABOUT NUTRITION-RELATED}

HAZARDS?

There is, in fact, plenty of evidence that people are unrealistically optimistic about nutrition-related hazards. In early work in this area, for example, Weinstein $(1980,1983$, 1984,1987 ) found unrealistic optimism for suffering from diabetes, heart attacks, tooth decay and food poisoning. More recently, Sparks \& Shepherd (1994) found optimism for a variety of food-related hazards (for example, in relation to nutrition, microbiological contamination, food additives) but especially for those relating to nutritional hazards. Part of the explanation for this may have to do with the amount of control that people perceive themselves as exerting over their susceptibility to these kinds of hazards. As we have indicated previously, it has been demonstrated that hazards that are perceived as controllable attract more optimism; evidence suggests that exposure to nutritional hazards is widely perceived to be highly controllable. Sparks et al. (1995) found unrealistic optimism for 'putting on weight', 'getting heart disease' and 'feeling unwell' (because of high fat consumption). Interestingly, they found that people seemed also to judge their intake of 'unhealthy' foods as lower than that of the average person. For example, people judged their intake of meat, margarine and/or butter, biscuits, buns, cakes and pastries and fat (in general) to be lower than that of the average person of their gender and age. Estimates of relative risk were significantly related to estimates of relative consumption such that, for example, estimates of the relative risk of heart disease were positively correlated with the estimated relative amount of fat consumed. But people do not always tend to report lower consumption than others; for example, they may report higher-than-average consumption of healthy items such as vegetables and fibre (P. Sparks and R. Shepherd, unpublished results). These findings, in conjunction with some claims that many people seem to be unaware of the levels of their dietary intake of fat (Lloyd et al. 1993), might account for some of the failure of nutritional messages, since people may accept the general validity of such messages while at the same time believing them to be more applicable to others than to themselves.

While it is difficult for people to recall precisely how frequently they consume a particular item of food, there is some evidence to suggest that what people actually do 'recall' in this regard will be motivated by some sort of wish to present themselves in a favourable light relative to others. Klein \& Kunda (1993) asked subjects (Princeton undergraduates) to state how often they consumed different foods (e.g. red meat, greasy foods, candy). For this survey, subjects were required to mark their responses on seven-point scales, ranging from '(1) never' to '(7) more than thirteen meals (per week)'. Some subjects were told what the average responses (for Princeton undergraduates) were, some were told that the average responses were one scale point higher than they actually were, some were told that the average responses were one scale point lower than they actually were, and some were given no information of this sort (control condition). 
The pattern of responses was such that subjects appeared to adjust their reported frequency of intake in line with what they believed others' intakes to be and in such a way 'so as to maintain their superiority over others'. For example, when told that average frequency reported for red meat consumption was $3 \cdot 23$, subjects' reported average scale rating was $2 \cdot 87$; when told $4 \cdot 23$, subjects' reported average scale rating was $3 \cdot 28$; when told $2 \cdot 23$, subjects' reported average scale rating was $2 \cdot 77$. Subjects in the control condition gave a mean rating of $3 \cdot 39$. So, there is some evidence that people will adjust their judgements (even of their own intake frequency) to maintain a position relative to others that puts them in a positive light. Relative standing seems important to people with respect to what they are consuming, but are they also concerned about their relative risk standing?

The extent to which people's beliefs about their susceptibility to risks relative to others are going to concern them and the extent to which their beliefs about their absolute levels of risk are going to concern them are issues that are currently being investigated. In a piece of recent research in which people were provided with scenarios about the possibility of getting pancreatic disorder, W. M. Klein (unpublished results) found that people reported that they would be more concerned about their levels of risk relative to others than about their absolute levels of risk. However, our own recent research, adopting a scenario method similar to that used by Klein, found that people reported that they would be more concerned (and that they would be more likely to change their diets) as a function of absolute levels of fat intake and not as a function of levels of intake relative to others. This remains an important issue that clearly requires further systematic investigation.

But how accurate are people in assessing their absolute risks? A. J. Rothman, W. M. Klein and N. D. Weinstein (unpublished results), for example, have assessed the extent to which unrealistic optimism arises because people underestimate their own risks or because they overestimate others' risks. They found that subjects tended to overestimate others' risks of a large number of hazards (for example, diabetes, liver disease, alcohol abuse), while there was some evidence that subjects tended to overestimate their own (personal) risks from lower probability hazards (such as dying from chronic liver disease or diabetes) and to underestimate their risks from higher probability hazards (such as getting a divorce or becoming infected with human papilloma virus). Over all, the pattern seemed to be that subjects made fairly accurate judgements about their own risks but that they overestimated others' risks.

\section{SOME OBSERVATIONS ON ETHICAL ISSUES}

'To an increasing number, the idea of sitting down and eating a meal has become more of a threat than a pleasure due to fear of harm from eating certain foods.' (Evans, 1988)

'As health communication research and practice moves into the 21 st century, we must face the fact that much of health communication research and practice is manipulative in nature and develop strategies for the ethical use of manipulation techniques to promote health and prevent disease.' (Witte, 1994)

We have already alluded to the practical problem of accurately measuring people's dietary intake as a prerequisite for many types of intervention strategy. Hand-in-hand with this particular problem, there are also ethical issues raised when people are 
provided with personal 'information' about their intake that may not be entirely accurate. While this is a specific issue that concerns intervention strategies that provide 'feedback' information, there are some more general ethical issues for health promotion efforts that need to be heeded.

It has been argued that those involved in health promotion need to be aware of problems associated with the 'rapidly developing health ideology in our culture' (Evans, 1988), such as the dangers of promoting strategies on the basis of research findings where the evidence is less than unequivocal, the individualistic orientation to health problems that such health promotion often involves (Becker, 1986; Evans, 1988; Leichter, 1991) and the danger of producing anxiety through raising public awareness of health risks (Becker, 1986; Kickbusch, 1986). If we accept the view of Taylor \& Brown (1988) that optimism may be related to well-being, we should consider the range of potential implications of reducing people's optimism. For example, providing information about the level of macronutrients in their diet may conceivably lead to negative affective consequences (for example, anxiety, worry) in addition to any possible effects on their behaviour. Such intervention strategies need to be judged in terms of the totality of their effects. However, potential 'sins of commission' in terms of any detrimental effects of giving such information need to be assessed in conjunction with 'sins of omission' if such information is withheld. Of course, information may cause worry, but it may also reassure and alleviate worry. The general ethical issues here are similar to those implicated in information provision more generally (the reader is invited to consider similar concerns about providing information about microbiological risks or pesticide residues, for example). One potential (though incomplete) solution to this problem is to provide information only to those who freely request it rather than providing it to those who are judged to 'need' it (although we can do no more in the present paper than acknowledge the conceptual problems that this suggestion raises!). More research is required into the accuracy and effects of information provision, alongside discussion of the associated ethical issues.

\section{WHAT ARE THE IMPLICATIONS FOR THE PROMOTION OF DIETARY CHANGE?}

'(This review suggests that) programs emphasising concrete, personalised information about likelihood, severity, and precautions; programs attacking unrealistic optimism; and programs finding ways to increase hazard salience will be more successful than will traditional attempts to disseminate general hazard information to the public.' (Weinstein, 1989)

The success of health promotion campaigns may be partially undermined by people's unrealistic optimism if health-promoting messages are understood, accepted, but deemed essentially applicable to other people rather than to oneself (Hoorens, 1994). As we have already noted, if people do not perceive themselves as vulnerable to a hazard, they are not likely to adopt behaviour changes in order to avoid the hazards.

One major problem is that people may have great difficulty in assessing their intake of nutritional components. This may be easier for portions of fruit and vegetables than it is for percentage of food energy from fat, for example, but even so there may be problems of recall which will bias these kinds of judgements. Perceptions of intake may relate to 
perceptions of risk, but both these perceptions are difficult for people to assess. As we have noted previously a number of pieces of research have begun to provide people with 'feedback' information about the fat content of their diets in the hope that this might instil some motivation to change dietary behaviour. For example, Bowen et al. (1994) conducted a feedback study in which subjects (undergraduate students) were told that their fat consumption was 'below recommended', 'at recommended', 'above recommended' or 'significantly above recommended' levels. They found that feedback information about fat intake led to a reduction in fat consumption, but for all groups (a control group was not included in the design)! Those subjects that had received 'high-fat' feedback showed greater negative emotional distress as a response to their feedback. These subjects also stated that they knew less about high-fat foods than subjects receiving 'lower' feedback. At 1 month after feedback, subjects in the highest feedback condition were less likely to report intentions to lower their dietary fat.

A number of problems are apparent in the research that has been developing in this direction. For example, there are a number of familiar practical issues to do with the accurate assessment of dietary intake that need to be overcome. Intake measures need to be accurate yet practicable within the resources of the intervention work. Kristal et al. (1990), for example, have developed a 'Short Dietary Questionnaire' which is reported to measure fat intake accurately; thorough validation of such measures would appear to be a useful investment of effort given the potential payoffs of their use in intervention work.

Attempts in more controlled experimental research to reduce unrealistic optimism have, by and large, been unsuccessful (for example, see Weinstein \& Klein, 1995). Our own research in this area has also produced only limited success, although this is an area of intervention that may prove to be a useful one to pursue.

Finally, that there is plenty of evidence for the unrealistic optimism phenomenon is not doubted. The main outstanding ambiguities concern (1) the reasons for, or causes of, the phenomenon, and (2) the consequences of the phenomenon. Those involved in applied work in health promotion tend to be interested primarily in the latter issue. What we have attempted to do in the present short paper is to outline some of the 'unrealistic optimism' issues that we believe are pertinent to the promotion of dietary change. There not only seems to be a trend for people to underestimate the dietary risks that they face (at least, relative to others' risks), but it appears that this underestimation may be related to the difficulties they encounter when trying to assess their own dietary intake. If these factors in combination are likely to promote inaction in response to dietary risks, there is then an urgent need to address this problem in health promotion campaigns.

The production of this paper was supported by the Ministry of Agriculture, Fisheries and Food through their funding of the research project 'Communication strategies for the effective promotion of dietary change' which addresses many of the themes raised here.

\section{REFERENCES}

Andrien, M. (1994). Nutrition: A Review of the Effectiveness of Health Education and Health Promotion. Utrecht: Landelijk Centrum GVO.

Becker, M. H. (1986). The tyranny of health promotion. Public Health Reviews 14, 15-23.

Bowen, D. J., Fries, E. \& Hopp, H. P. (1994). Effects of dietary fat feedback on behavioral and psychological variables. Journal of Behavioral Medicine 17, 589-604. 
Bowen, D. J. \& Tinker, L. F. (1995). Controversies in changing dietary behavior. In Controversies in Nutrition [F. Bronner, editor]. New York: Elsevier Inc. (In the Press).

Buzzard, I. M., Chlebowski, R. T., Jeffery, R. W., Blackburn, G. L., Scanlon, E. F., Elashoff, R. M. \& Wynder, E. L. (1990). Diet intervention methods to reduce fat intake: nutrient and food group composition of self-selected low-fat diets. Journal of the American Dietetic Association 90, 42-51.

Cannon, G. (1992). Food and Health: The Experts Agree. London: The Consumers' Association.

Department of Health (1992). The Health of the Nation. London: H.M. Stationery Office.

Department of Health (1994). Nutritional Aspects of Cardiovascular Disease. Report on Health and Social Subjects no. 46. London: H.M. Stationery Office.

Evans, R. I. (1988). Health promotion - science or ideology? Health Psychology 7, 203-219.

Glanz, K. (1985). Nutrition education for risk factor reduction and patient education: A review. Preventive Medicine 14, 721-752.

Glanz, K. \& Eriksen, M. P. (1993). Individual and community models for dietary behavior change. Journal of Nutrition Education 25, 80-86.

Glanz, K., Hewitt, A. M. \& Rudd, J. (1992). Consumer behavior and nutrition education: an integrative review. Journal of Nutrition Education 24, 267-277.

Henderson, M. M., Kushi, L. H., Thompson, D. J., Gorbach, S. L., Clifford, C. K., Insull Jr, W., Moskowitz, M. \& Thompson, R. S. (1990). Feasibility of a randomized trial of a low-fat diet for the prevention of breast cancer: dietary compliance in the Women's Health Trial Vanguard Study. Preventive Medicine 19, 115-133.

Hoorens, V. (1994). Unrealistic optimism in health and safety risks. In Social Psychology and Health: European Perspectives [D. R. Rutter and L. Quine, editors]. Aldershot: Avebury Press.

Kickbusch, I. (1986). Life-styles and health. Social Science and Medicine 22, 117-124.

Klein, W. M. \& Kunda, Z. (1993). Maintaining self-serving social comparisons: biased reconstruction of one's past behaviors. Personality and Social Psychology Bulletin 19, 732-739.

Kristal, A. R., Abrams, B. F., Thornquist, M. D., Disogra, L., Croyle, R. T., Shattuck, A. L. \& Henry, H. J. (1990). Development and validation of a food use checklist for evaluation of community nutrition interventions. American Journal of Public Health 81, 1318-1322.

Leichter, H. M. (1991). Foolishness and politics. In Free to be Foolish. Politics and Health Promotion in the United Kingdom and Great Britain [H. M. Leichter, editor]. Princeton, NJ: Princeton University Press.

Lloyd, H. M., Paisley, C. M. \& Mela, D. J. (1993). Changing to a low fat diet: attitudes and beliefs of UK consumers. European Journal of Clinical Nutrition 47, 361-373.

McGrath, J. C. (1991). Evaluating national health communication plans. American Behavioral Scientist 34, 652-665.

Sparks, P. \& Shepherd, R. (1994). Public perceptions of the potential associated with food production and food consumption: an empirical study. Risk Analysis 14, 799-806.

Sparks, P., Shepherd, R., Wieringa, N. \& Zimmermanns, N. (1995). Perceived behavioural control, unrealistic optimism and dietary change: an exploratory study. Appetite 24, 243-255.

Taylor, S. E. (1989). Positive Illusions. New York: Basic Books.

Taylor, S. E. \& Brown, J. D. (1988). Illusion and well-being: A social psychological perspective on mental health. Psychological Bulletin 103, 193-210.

Taylor, S. E., Kemeny, M. E., Aspinwall, L. G., Schneider, S. G., Rodriguez, R. \& Herbert, M. (1992). Optimism, coping, psychological distress, and high-risk sexual behaviour among men at risk for acquired immunodeficiency syndrome (Aids). Journal of Personality and Social Psychology 63, 460-473.

Tyler, T. R. \& Cook, F. L. (1984). The mass media and judgements of risk: Distinguishing impact on personal and societal level judgements. Journal of Personality and Social Psychology 47, 693-708.

Van der Pligt, J. (1994). Healthy thoughts about unhealthy behavior. Psychology and Health 9, 187-190.

Weinstein, N. D. (1980). Unrealistic optimism about future life events. Journal of Personality and Social Psychology 39, 806-820.

Weinstein, N. D. (1983). Reducing unrealistic optimism about illness susceptibility. Health Psychology 2, $11-20$.

Weinstein, N. D. (1984). Why it won't happen to me: perceptions of risk factors and susceptibility. Health Psychology 3, 431-457.

Weinstein, N. D. (1987). Unrealistic optimism about susceptibility to health problems: conclusions from a community-wide sample. Journal of Behavioral Medicine 10, 480-499.

Weinstein, N. D. (1989). Optimistic biases about personal risks. Science 246, 1232-1233.

Weinstein, N. D. \& Klein, W. M. (1995). Resistance of personal risk perceptions to debiasing interventions. Health Psychology 14, 132-140. 
Weinstein, N. D. \& Nicolich, M. (1993). Correct and incorrect interpretations of correlation between risk perception and risk behaviors. Health Psychology 12, 235-245.

Winett, R. A., Southard, D. R. \& Rankin, J. W. (1993). Nutrition promotion and dietary change: Framework to meet year 2000 goals. Medicine, Exercise, Nutrition, and Health 2, 7-26.

Witte, K. (1994). The manipulative nature of health communication research: ethical issues and guidelines. American Behavioral Scientist 38, 285-293. 